
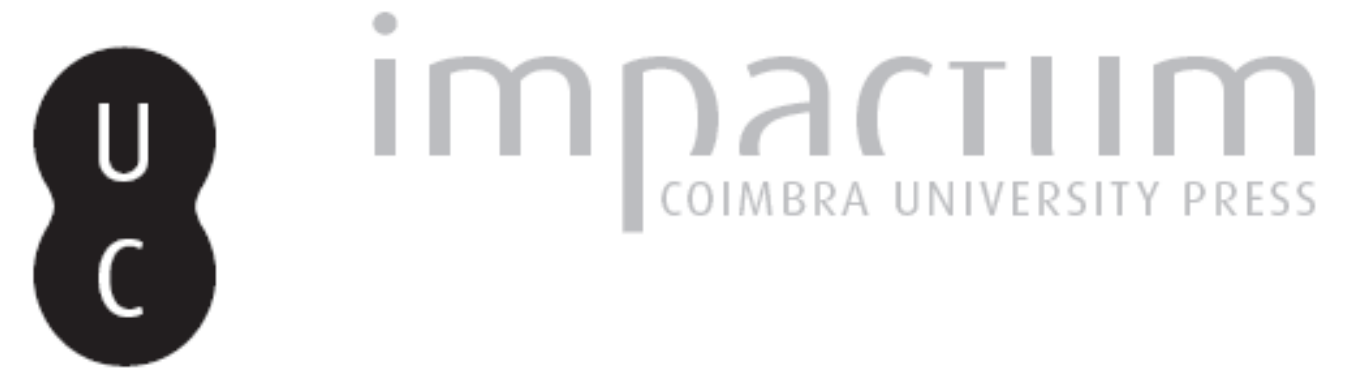

\title{
Oito fíbulas da região de Braga
}

\section{Autor(es): $\quad$ Ponte, Salete da}

Publicado por: Faculdade de Letras da Universidade de Coimbra

URL persistente:

URI:http://hdl.handle.net/10316.2/37748

DOI:

DOI:http://dx.doi.org/10.14195/1647-8657_46_6

Accessed : $\quad$ 26-Apr-2023 10:41:17

A navegação consulta e descarregamento dos títulos inseridos nas Bibliotecas Digitais UC Digitalis, UC Pombalina e UC Impactum, pressupõem a aceitação plena e sem reservas dos Termos e Condições de Uso destas Bibliotecas Digitais, disponíveis em https://digitalis.uc.pt/pt-pt/termos.

Conforme exposto nos referidos Termos e Condições de Uso, o descarregamento de títulos de acesso restrito requer uma licença válida de autorização devendo o utilizador aceder ao(s) documento(s) a partir de um endereço de IP da instituição detentora da supramencionada licença.

Ao utilizador é apenas permitido o descarregamento para uso pessoal, pelo que o emprego do(s) título(s) descarregado(s) para outro fim, designadamente comercial, carece de autorização do respetivo autor ou editor da obra.

Na medida em que todas as obras da UC Digitalis se encontram protegidas pelo Código do Direito de Autor e Direitos Conexos e demais legislação aplicável, toda a cópia, parcial ou total, deste documento, nos casos em que é legalmente admitida, deverá conter ou fazer-se acompanhar por este aviso.

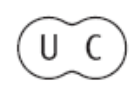




\section{CONIMBRIGA}

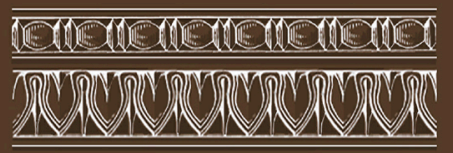

INSTITUTO DE ARQUEOLOGIA

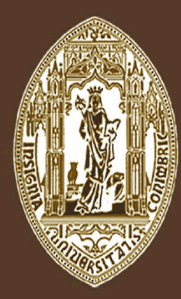

VOLUME XLVI - 2007

FACULDADE DE LETRAS UNIVERSIDADE DE COIMBRA 
SAlete Da Ponte

Instituto Politécnico de Tomar. Departamento de Gestão Turística e Cultural

\section{OITO FÍBULAS DA REGIÃO DE BRAGA}

"Conimbriga" XLVI (2007) p. 117-128

Resumo: A autora publica oito fíbulas, de bronze, provenientes de vários sítios proto-históricos e romanos da região de Braga.

Estas peças enquadram-se, respectivamente, nos tipos 22 (Sabroso), 23 (Santa Luzia), 32 (transmontano), 33 (Meseta), 42 (Aucissa) e 53 (zoomórfica esmaltada), ocupando um período cronológico desde o séc. VII/1. ${ }^{a}$ metade do VI a. C. até ao séc. II/III d. C.

RÉSUMÉ: L'auteur publique huit fibules, en bronze, provenants de plusieurs sites protohistoriques et romains de la région de Braga.

Ces pièces appartiennent, respectivement, aux types 22 (Sabroso), 23 (Santa Luzia), 32 (transmontano), 33 (Meseta), 42 (Aucissa) et 53 (zoomorphes émaillées), et datent dès du VIIe/début du VIe siècle, avant notre ère, jusqu'au milieu du II $\%$ /IIIe siècle de notre ère. 
(Página deixada propositadamente em branco) 


\section{OITO FÍBULAS DA REGIÃO DE BRAGA}

\section{Introdução}

Estas peças, de bronze, são pelos seus caracteres tecnomorfológicos, indicadores de diferentes períodos cronoculturais da região, no quadro evolutivo de ocupação do Norte de Portugal, entre a Idade do Ferro e a Romanização. Das oito peças, três são inéditas, para além de apresentarem particularidades de natureza tipo-morfológico e decorativo, não referenciadas na recente tabela tipo-cronológica proposta no meu trabalho de investigação sobre o universo das fíbulas existentes no país (PONTE 2006). Deste modo, os objectos aqui ilustrados, serão, não só inseridos na tabela tipológica, mas também obedecerão à metodologia e nomenclatura daquela, ampliando, assim, o universo daqueles objectos de adorno pessoal. Será igualmente privilegiada a análise tecnomorfológica, por conexão com achegas de contextos culturais locais e regionais bem definidos.

Algumas destas, peças achadas em contextos arqueológicos, vêm corroborar a cronologia recentemente atribuída, proporcionando um conhecimento mais ajustado a estas produções metálicas.

\section{Ambiência Cultural e Estrutura}

Os exemplares ilustrados reflectem duas fases cronoculturais da região Norte de Portugal, donde os povoados/castros e os núcleos urbanos romanos pontificam nos vários locais do actual distrito bracarense. São elas, a Idade do Ferro (Est. I, n. ${ }^{o s} 1$ a 4 ) e o período Romano (Est. I, n.os 5 a 8).

Os quatro primeiro exemplares (Est. I, n. ${ }^{\text {os }} 1$ a 4), são provenientes do povoado de Santo Ovídio, em Fafe (n. ${ }^{\text {os }} 1$ e 3), do Castro da Sola, em Braga (n. ${ }^{\circ}$ 2), e do povoado de S. Julião, em Vila Verde (n. ${ }^{\circ}$ ), reve- 
lando novos padrões tecnomorfológicos, associados a novos intervenientes no palco dos mecanismos de produção, controlo e distribuição de mercadoria durante o séc. VIII a. C./VII a. C., com reflexos na metalurgia do ferro e ourivesaria. É neste contexto que vários artefactos metálicos, por meio de agentes de circulação (VILAÇA 1998: 348), provenientes de zonas atlântico-mediterrânicas, provocam a especialização de metalurgistas, a proliferação de oficinas locais, e, consequentemente o colapso e falência sócio-económica de certas comunidades indígenas dos sécs. VIII-VII a. C. (PonTe 2006: 297).

A nova geografia etnocultural e o reordenamento dos povoados fortificados do Norte/Centro Beira Interior, manifestam-se também na fisionomia tecnocultural das fíbulas, que reflectem o cruzamento de influências atlântico-mediterrânicas, durante os meados dos sécs. VII/ /inícios do VI a. C.

Esta fisionomia tecnocultural é evidenciada pela abundância de fíbulas de apêndice caudal, de bronze, como sejam as de tipo Sabroso (Ponte 22), Santa Luzia (Ponte 23), transmontana (Ponte 32) e as de tipo Meseta (Ponte 33).

Os exemplares aqui ilustrados (Est. I, n. ${ }^{\text {os }} 1$-4) permitem traçar a sua evolução tecnocultural e familiarizar a sua progressão mecânica e cronomorfológica com o foco cultural da Meseta Centro e Norte, mais exactamente com a Cultura do Douro. Deste modo, este segmento evolutivo das fíbulas de apêndice caudal, disperso e intenso nos povoados a norte do Tejo (PonTe 2006: 295-296), reflecte entre os sécs. VII-III a. C., a profusão da metalurgia do ferro nos castros do Noroeste Peninsular (SILVA 1986: 171), graças à especialização da metalurgia do bronze e da ourivesaria.

Os concelhos de Fafe (Santo Ovídio), Vila Verde (S. Julião) e Braga (Castro da Sola) indicam uma intensa ocupação do Norte e do Noroeste relativa à Idade do Bronze e Idade do Ferro, apesar do deficiente conhecimento sobre os padrões e modalidades de povoamento das comunidades proto-históricas nestas áreas geo-culturais.

Os contextos e conteúdos geoculturais destes povoados fortificados do NO permitem-nos, no panorama europeu e peninsular, o reconhecimento de balizas cronoculturais de povoamento e de desenvolvimento das comunidades de diferentes áreas culturais, favorecidas por intercâmbios com o Mediterrâneo e o Atlântico. É neste quadro peninsular e europeu da metalurgia do bronze e do ferro, que nos reportamos aos caracteres tecnomorfológicos e etno-culturais de artesania metálica 
referenciada e identificada, sobretudo a proveniente de escavações arqueológicas recentes (SiLVA 1986; MARTINS 1990 e 1991).

Estes materiais metálicos (Est. I, n.os 1-4) definem uma ambiência cultural da Idade do Ferro, evidenciando e estabelecendo diferentes etapas tecnomorfológicas, num grande quadro temporal de desenvolvimento cronocultural dos povoados do Norte de Portugal (PonTE 2006: 294).

Situam-se, na primeira linha evolutiva das primitivas fíbulas de apêndice caudal (PONTE 2006: 218-233; 271-287 - tipos 22-23; tipo 23/33), os modelos de tipo Sabroso (tipo 22), directamente associados à cultura castreja galaico-portuguesa. Estes modelos singulares desencadearam, então, múltiplos segmentos tecnomorfológicos, muitos deles resultantes de produções locais e de criações sui generis, com afinidades estruturais e morfológicas a grupos celto-germânicos e a movimentos populacionais originários do Mediterrâneo Ocidental, portadores de uma nova filosofia de fabrico metalúrgico.

As fíbulas de tipo 22 (tipo Sabroso), basicamente com duas sub-modalidades (a-b), é a sucessora das fíbulas de pé alto, ou seja, dos modelos evoluídos de tipo Alcores (tipo 8), Acebuchal (tipo 9), Bencarrón (tipo 10) e Golfo de Leão (tipo 11).

O exemplar n. ${ }^{\circ} 1$ (tipo 22a), proveniente do Castro de Santo Ovídio (Fafe), conserva indícios claros do processo de enrolamento da sua mola bilateral, simétrica, de corda interior ao arco (PONTE 2006: 219-220, fig. 57). O arco, a mola, o pé e o apêndice caudal, constituem uma única peça sólida. O seu processo de fabrico consistia, tanto por meio da forjadura, como por fundição, usando neste último caso, o molde bivalve, ou o processo de cera perdida.

É provável que nos modelos de recorte morfológico mais singelo, os artífices adoptassem a combinação dos dois métodos de fabrico.

Situamos este exemplar de Santo Ovídio (Est. I, n. ${ }^{\circ} 1$ ), como um dos modelos mais antigos da cadeia evolutiva de apêndice caudal, entre o séc. VII a. C., e a primeira metade do séc. VI a. C., com pervivências nos meados do séc. III a. C. (PonTE 2006: 222, quadros 62-63).

Carecendo esta fíbula de uma datação "in loco" segura e precisa (MARTINS 1991: 87-90; contaminação antiga da prova arqueológica descontextualizada), não é menos certo que outros povoados da I Idade do Ferro do NO nos fornecem indicadores preciosos sobre o horizonte cronotecnológico desta produção metálica. 
Ilustramos um outro exemplar (Est. I, n. ${ }^{\circ} 3$ ) do mesmo povoado proto-histórico (MARTINS 1991: 104), bem mais evoluído, designado por fíbula de tipo transmontano (tipo 32c), decorrente da área ibérica (PONTE 2006: 274, quadro 85). Digamos que este modelo frequente no universo castrejo peninsular, evidencia na faixa norte do vale do Tejo, e no enclave Sado-Guadiana uma fisionomia bem sui generis, assumindo a convergência de contributos tecnoculturais próprios: um, de cariz proto-céltico e céltico e outro ibero-tartéssico (PONTE 2006: 277-280). Esta produção metálica está na mesma linha evolutiva das fíbulas de tipo Sabroso (tipo 22) e de tipo Santa Luzia (tipo 23). Apresenta particularidades decorativas e estruturais, que a individualizam no meio de toda a produção peninsular. A sua estrutura comporta basicamente 4 elementos: arco-pé; eixo; mola bilateral e fusilhão. Este último elemento separa-se de mola bilateral e torna-se independente.

Este novo processo mecânico torna a peça metálica mais consistente e equilibrada nos movimentos de manipulação do fusilhão.

O uso corrente de um eixo, de ferro, a conversão e projecção volumétrica e decorativa do arco e do apêndice caudal, e a subtileza do pé e descanso, preconizam já um apuramento técnico e estilístico bem marcante neste espaço cultural. A densidade e dispersão deste fabrico homogéneo, com ramificações estilísticas e morfológicas específicas, permitem-nos estabelecer hipoteticamente áreas geográficas de significado etnocultural e sócio-ideológico (PONTE 2006: 272-280, quadro 85). Digamos que o modelo do povoado de Santo Ovídio (tipo 32c), reflecte uma iconografia morfológica e estilística do universo mediterrânico, conservando a matriz da área cultural celtibérica e das zonas periféricas da Meseta Setentrional e Meridional. A sua longevidade temporal (Finais do I a. C.-Finais do I d. C.), e a consequente produção metálica, estão directamente relacionadas com o novo processo sócio-ideológico das populações indígenas dos oppida (Finais do III-II a. C.), do qual emerge uma nova estrutura e organização sócio-económica. Esta nova elite urbana surge na fase final da cultura ibérica e celtibérica (ALMAGRo GoRBEA 1994: 13-75), surgindo este objecto de adorno pessoal na indumentária militar. Por outro lado, os novos elementos iconográficos e decorativos reflectem uma nova política de desenvolvimento do território, do qual emergem como agentes de romanização, a generalização de técnicas e de ferramentas artenais e industriais, com evidência para a cerâmica e a ourivesaria. 
Este exemplar (Est. I, n. ${ }^{\circ}$ 3) é proveniente de um contexto romanizado (MarTins 1991: 104) preconizando já um conceito de urbanidade romana, sendo usado não só na indumentária militar, mas também na civil.

As outras duas fíbulas proto-históricas (Est. I, n.os 2 e 4), provenientes, respectivamente, dos povoados da Sola (Braga) e de S. Julião (Vila Verde), ainda inéditas, permitem-nos comparar com outros espécimens contemporâneos, e detectar indícios de inovação, de identidade e singularidade geocultural, num vasto universo de fíbulas de apêndice caudal da I Idade do Ferro, sobretudo em áreas célticas, celtibéricas e ibéricas do Extremo Ocidente Peninsular.

A peça de tipo 23 (Est. I, n. ${ }^{\circ} 2$ = tipo Santa Luzia) insere-se na mesma cadeia tipológica das fíbulas de tipo Sabroso (tipo 22), revelando já uma série de caracteres inovadores, no domínio da estrutura, mecânica e decoração.

$\mathrm{O}$ arco destaca-se dos restantes elementos estruturais, como peça independente, obtida pelo processo de fundição em molde bivalve ou pela técnica de cera perdida; o pé alto ou apêndice caudal, adquire, por seu turno, novos padrões estilísticos, revelando afinidades e influências de vários modelos peninsulares (PONTE 2006: 224-226). Os restantes elementos estruturais, obtidos por forjadura, permitem no novo processo funcional (mola-fusilhão e eixo) maior estabilidade e equilíbrio mecânico, no movimento de vaivém do fusilhão.

O estádio evolutivo do arco e da mola-fusilhão reduz, em relação ao padrão sabrosino (tipo 22), as várias tensões e respectivas fracturas na cabeça do arco e fusilhão.

Este novo modelo metálico (tipo 23) teria aparecido no Noroeste Peninsular, muito provavelmente nos finais do séc. VII/inícios do VI a. C., com ocorrências frequentes durante o séc. V a. C./IV a. C. (PonTE 2006: 229, quadro 65), e pervivências bem mais tardias nalguns castros do Noroeste Peninsular (Silva 1986: 189). Esta longevidade deve-se, sobretudo, às assimetrias cronoculturais existentes no povoamento do Ocidente Peninsular (entre I e II Idade do Ferro), muito provavelmente relacionados com as transformações políticas e sócio-económicas operadas na Europa Central e no mundo Mediterrânico. Há, porém, outros factores decorrentes de uso ocasional, ou sazonal do lugar, que possibilitam interferências diacrónicas e substantivas de substratos estranhos ao horizonte cronocultural daquele sítio. Assim se poderá depreender do local, donde provém esta fíbula, de bronze (Est. I, n. ${ }^{\circ}$ 2, tipo $23=$ 
tipo Santa Luzia), a par de outras peças mais, igualmente contextualizadas (BETTENCOURT 1991-92: 100-102), o importante significado geocultural destas inovações técnicas e mecânicas, exclusivas da I Idade do Ferro (PONTE 2006: 224-229).

As evidências arqueológicas do castro da Sola (=Fase I-III) não são claras, nem precisas, quanto à presença de um dos modelos típicos da I Idade do Ferro, como são as fíbulas evoluídas de apêndice caudal (tipos 23, 23/32; tipos 24, 25-26; tipos 32-33).

Deve-se também sublinhar que a escassez de objectos metálicos, e mais concretamente de fíbulas proto-históricas em determinados povoados do NO (PONTE 2005: 185-205), acabam por dificultar o estabelecimento de parâmetros cronológicos seguros, e obstar ao reconhecimento efectivo de povoados de curta e longa duração.

Esta raridade repete-se em S. Julião - Vila Verde (BETTENCOURT 2001; PONTE 2005: 193-197), embora os vestígios arqueológicos identificados apontem, no entanto, para a existência de uma actividade metalúrgica desde o Bronze Final, neste povoado proto-histórico, de longa duração (MARTINS 1986: 159-160; id., ibidem, 1990: 97; BETTENCOURT 2001: 22).

A fíbula aqui ilustrada (Est. I, n. $\left.{ }^{\circ} 4\right)$, conservando apenas o apêndice caudal, constitui um belíssimo exemplar inédito, de tipo 33b (tipo Meseta). Os seus caracteres tecnomorfológicos fazem-no situar num contexto cronológico dos finais do séc. VII/inícios do VI a. C., com larga dispersão nos sécs. V-IV a. C., podendo ainda coexistir com outros modelos nos inícios do séc. III a. C. (PoNTE 2006: 285-287).

O subtipo 33b, apresenta uma característica estrutural e morfológica propícia ao uso da fundição em molde de areia, molde bivalve, não descartando, porém, o processo de cera perdida (PONTE 2006: 280-285).

O motivo decorativo deste apêndice caudal revela já um processo metalúrgico evoluído, a rivalizar com outras produções do noroeste peninsular, como as fíbulas de tipo 32 (tipo transmontano), e os padrões decorativos da produção cerâmica e da ourivesaria do NO português (SiLva 1986).

Este fragmento metálico, de bronze (Est. I, n. ${ }^{\circ}$ ), achado na Fase II deste povoado (MARTINS 1990: 149), poderá estar relacionado com a produção metalúrgica do bronze local, onde os padrões decorativos cerâmicos e de ourivesaria, são, no nosso entender, um dos factores de atributo técnico e decorativo geocultural do NO. 
As restantes outras peças metálicas, de bronze (Est. I, n. ${ }^{\text {os }} 5-8$ ), provenientes de Bracara Augusta (Quinta do Funjacal, Antigas Cavalariças, Colina de Maximinos e termas Bracara Augusta), revelam um novo quadro sócio-político e uma nova geografia histórica das comunidades urbanas no extremo ocidente da Peninsula Ibérica.

Estes exemplares romanos, de tipo 42 e 53 (Est. I, n. ${ }^{\text {os }} 5$ a 8), revelam igualmente novos sistemas e níveis técnicos diferenciados de anteriores produções indígenas e proto-romanas ( La Tène III/La Tène Final). Inserem-se no vasto universo de fíbulas de charneira, apresentando estas peças metálicas duas categorias bem distintas: uma (Est. I, n. ${ }^{\text {os }}$ 5-7; tipo 42), correspondente à charneira romana, apresenta-se sob a forma de plaquinha e eixo, donde se sujeita o fusilhão e os botões terminais (tipo Aucissa); a outra (Est. I, n. ${ }^{\circ}$ 8; tipo 53), equiparada às fíbulas geométricas e zoomórficas (FEUGÈRE 1985: 335-416; ETTLINGER 1973: 110-130), evidencia uma charneira de tope osculator. Estes dois mecanismos de charneira, distintos e complexos, conhecem uma grande difusão no vasto império romano.

A charneira romana (tipo 42), representa uma nova etapa evolutiva das fíbulas, com uma matriz morfológica e tecnológica comum: perfil semicircular do arco e articulação da cabeça em charneira - placa quadrangular - com eixo e fusilhão recto; pé e descanso curtos; descanso triangular; botões terminais no pé e eixo.

O cariz tecnomorfológico destas fíbulas sugere uma produção industrial em série, usando o processo de cera perdida, ou, a fundição em molde bivalve, com o acabamento de pormenores, feito por meio de forja (PonTE 2006: 354-372, quadro 109).

As peças provenientes da Colina de Maximinos (tipo 42c/1a), da Quinta do Funjacal e das Antigas Cavalariças do RIB (tipo 42c/1b2), apresentam pequenas variantes morfológicas (Est. I, n. ${ }^{\text {os }} 5-7$ ), com pormenores decorativos bastante singelos e peculiares, muito próximos das peças oriundas do NO (PONTE 2006: 367-368, quadro 109).

A fíbula de tipo 42c/1a (Est. I, n. ${ }^{\circ}$ 5), similar a exemplares da Citânia de Briteiros e de Conimbriga, situam-se em contextos do séc. I d. C., nomeadamente em níveis flavianos (PonTE 2006: 359), ou, em patamares cronológicos um pouco mais tardios (PONTE 2006: 360, quadro 108).

O exemplar proveniente da colina de Maximinos, enquadra-se em níveis de ocupação romana, referente à Fase IV de Bracara Augusta (MARTINS 1990: 169-175). 
As outras duas peças (Est. I, n. ${ }^{\text {os }} 6-7=$ tipo $42 \mathrm{c} / 1 \mathrm{~b}$ ), de bronze, apresentam certas particularidades decorativas e morfológicas, sobretudo nos detalhes da placa da charneira e da cartela, e na fisionomia do descanso, que nos parece mais uma subvariante da terceira submodalidade do tipo 42 (PoNTE 2006: 361-362, quadro 107); a matriz decorativa da charneira, da cartela e dos botões terminais apresentam afinidades estilísticas dos principais centros de produção destas peças em vários sítios provinciais do universo romano.

Esta produção ocorre com frequência nos meados do séc. I d. C. em vários locais romanos, fixando-se, na Lusitânia portuguesa, entre o período claudiano e o flávio-trajânico (PONTE 2006: 361-362, quadro 108).

O exemplar brônzeo, das Antigas Cavalariças do RIB (Est. I, n. ${ }^{\circ}$ 7), encontra-se dentro do contexto urbanístico de Bracara Augusta (Delgado e Gaspar 1986: 151-167; Delgado e Martins 1988: 81), correspondente "à primeira fase de ocupação, que teve lugar no séc. I d. C.".

O último exemplar ilustrado (Est. I, n. ${ }^{\circ}$ 8), proveniente do edifício termal de Bracara Augusta, corresponde ao grupo de fíbulas zoomórficas esmaltadas (tipo 53), pouco conhecidas em Portugal (PONTE 2007). Julgamos que esta raridade deverá estar mais relacionada com a dificuldade de identificação destes objectos pelos achadores, sobretudo quando se apresentam desprovidos do seu sistema de fixação.

Este grupo caracteriza-se por uma lâmina plana, representando um peixe estilizado. $\mathrm{O}$ motivo decorativo, geométrico e inciso, marcam a cauda e as escamas; os círculos ou alvéolos concêntricos, representam os olhos, que teriam aplicações de esmalte (LERAT 1956: 41, est. XVIII, 31; ERICE LACABE 1995: 198-201).

A articulação do fecho é feita no reverso da lâmina esmaltada e figurativa. Compõe-se de duas plaquinhas paralelas, atravessadas pelo eixo, donde se fixa o fusilhão recto; o descanso é curto, rectangular ou trapezoidal, estando este incompleto.

A sua produção é frequente nos finais do séc. I e II d. C., podendo aparecer em contextos mais tardios do séc. III d. C. (ERICE LACABE 1995: 199). Este exemplar, achado em contexto do período flávio-trajano, apresenta três fases de fabrico distintas: as duas primeiras, correspondem ao processo de fundição em molde e forjadura, para a concepção da fíbula zoomórfica; a última, corresponde ao esmaltado ou 
"técnica de fusão de vidros sob uma base metálica" (ERICE LACABE 1995: 187). Não é possível conhecer a oficina que produziu o belo exemplar achado nas instalações termais de Bracara Augusta.

\section{BIBLIOGRAFIA}

Almagro-GorbeA, Martín - "El urbanismo en la Hispania Céltica: castros y oppida en la Península Ibérica”, (Almagro-Gorbea, M.; Martin Bravo, A. M., eds.), Castros y oppida en Extremadura, Madrid: Editorial Complutense, 1994, pp. 13-75.

Bettencourt, Ana M. S. - "O Povoado da Sola, Braga: notícia preliminar das escavações de 1991-92", Cadernos de Arqueologia, Braga, 1991-92, série II, 8-9, pp. 97-118.

Bettencourt, Ana M. S. - "Aspectos da metalurgia do bronze durante a Proto-História do Entre Douro e Minho", Arqueologia, Porto, 2001, 26, pp. 13-55.

Delgado, Manuela e GASPAR, Ana L. - "Intervenção arqueológica na zona PI (Antigas Cavalariças do Regimento de Infantaria de Braga)", Cadernos de Arqueologia, Braga, 1986, série II, 3, pp. 151-167.

Delgado, Manuela e MARTINS, Manuela - "Intervenção arqueológica na zona PI (Antigas Cavalariças do Regimento de Infantaria de Braga)", Cadernos de Arqueologia, Braga, 1988, série II, 5, pp. 77-90.

ERICE LACABE, Romana - Las Fíbulas del Nordeste de la Península Ibérica: siglos I a. e. al IV d. e., Zaragoza, 1995.

ETTLINGER, Elizabeth - Die Römischen Fibeln in der Schweiz, Berna, 1973.

Feugère, Michel - "Les Fibules en Gaule Meridionale de la Conquête à la fin du Ve siècle après J.-C.", Révue Archéologique de Narbonnaise (Supplément 12). Ed. CNRS. Paris, 1985.

Lerat, L. - "Lês Fibules Gallo-Romaines" (II) - Catalogue des Collections Archéologiques de Besançon", Annales Littéraires de l'Université de Besançon ( $2^{\mathrm{e}}$ série), 3, 1 (Archéologie 3), Paris, 1956.

MARTINS, Manuela - “A citânia de S. Julião, Vila Verde. Primeiras Sondagens”, Cadernos de Arqueologia, Braga, 1984, Série II, 1, pp. 11-27.

Martins, Manuela - "Duas datas de C14 para a ocupação do Bronze Final do povoado de S. Julião, Vila Verde", Arqueologia, 13, Porto, 1986, pp. 159-160.

Martins, Manuela - O Povoamento Proto-histórico e a Romanização da Bacia do Curso Médio do Cavado, Monografia (Cadernos de Arqueologia, 5), Braga, 1990.

Martins, Manuela - O Povoado de Santo Ovídio, Monografia (Cadernos de Arqueologia 6), Braga, 1991.

Ponte, Salete - "As Fíbulas do Bronze Final e Idade do Ferro de Portugal Interior (Norte e Centro)", CôaVisão (Cultura e Ciência). Edição Câmara Municipal de Vila Nova de Foz Côa, 2005, 7, pp. 186-205. 
Ponte, Salete - Corpus Signorum das Fíbulas Proto-históricas e Romanas de Portugal. Edição Caleidoscópio. Coimbra (G. C. Gráfica de Coimbra), 2006.

Ponte, Salete - "Las Fíbulas romanas de Portugal", Metalistería de la Hispania Romana (Carmelo Fernández Ibañez, ed.), Santander, 2007, Cap. 4 (no prelo). Silva, Armando C. F. - A Cultura Castreja no Noroeste de Portugal. Paços de Ferreira, 1986.

VILAÇA, Raquel - "Produção, consumo e circulação de bens na Beira Interior na transição do II para o I milénio a. C.," Actas do Colóquio A Pré-História na Beira Interior (Tondela, Nov. 1997), Viseu, 1998, 6, pp. 347-374. 

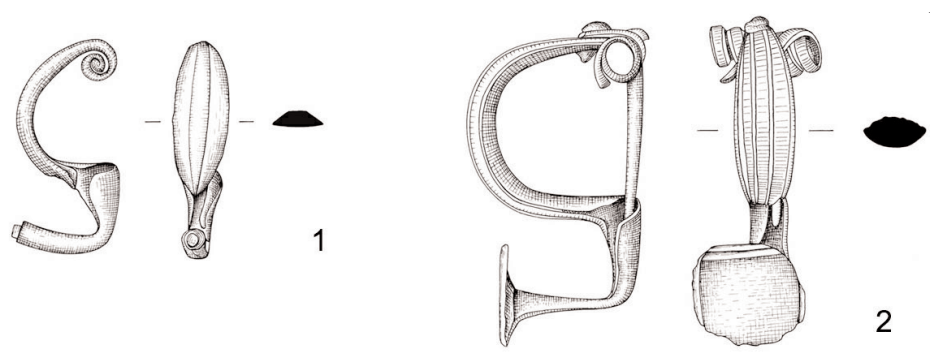

EST. I

1
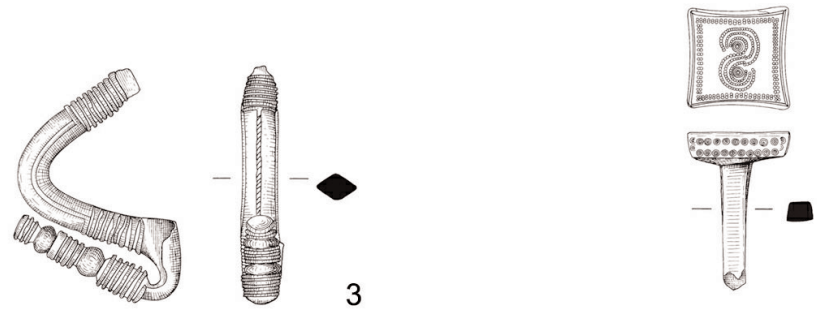

4
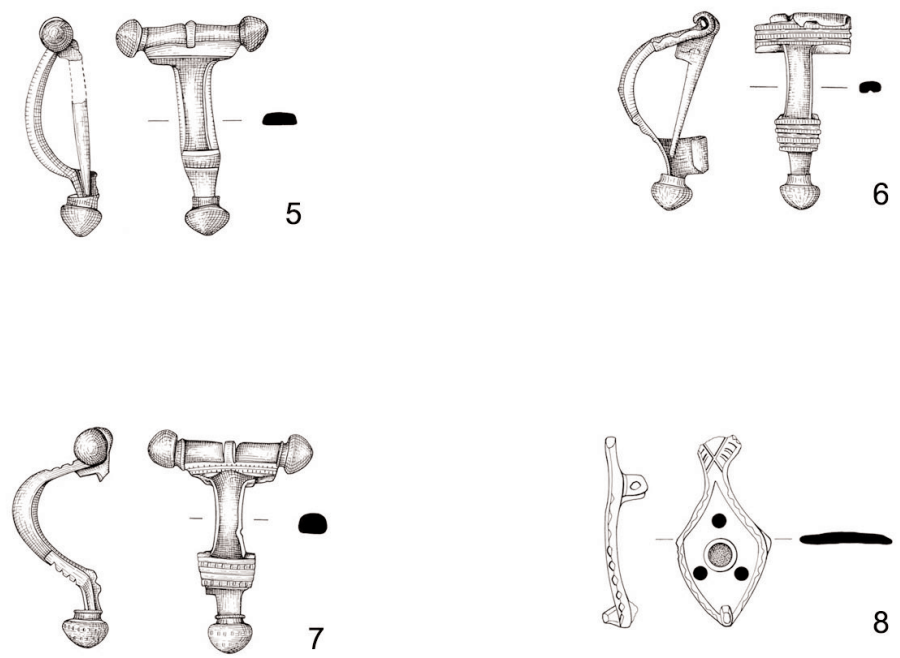

\section{$\overline{1 \mathrm{~cm}}$}

Fíbulas da Idade do Ferro provenientes, respectivamente, de Santo Ovídio, em Fafe ( . $^{\text {s }} 1$ e 3 = tipo 22 a e tipo 32c), do Castro da Sola, em Braga (n. ${ }^{\circ}$ 2, tipo 23), e do povoado de S. Julião, em Vila Verde $\left(n .^{\circ} 4\right.$, tipo $\left.33 b\right)$

Fíbulas romanas provenientes, respectivamente, da Colina de Maximinos $\left(n .^{\circ} 5\right.$, tipo 42c/1a), da Quinta do Funjacal ( $n .{ }^{\circ}$ 6, tipo 42c/lb), das Antigas Cavalariças $\left(n .^{\circ} 7\right.$, tipo 42c/1b2) e das instalações termais romanas de Bracara Augusta (.$^{\circ} 8$, tipo 53). 